\title{
Interspecific differences in photosynthetic efficiency and spectral reflectance in two Umbilicaria species from Svalbard during controlled desiccation
}

\author{
Radek Jupa, Josef Hájek, Jana Hazdrová, Miloš Barták* \\ Department of Experimental Biology, Laboratory of Photosynthetic Processes, Faculty \\ of Science, Masaryk University, University Campus - Bohunice, Kamenice 5, 62500 \\ Brno, Czech Republic
}

\begin{abstract}
This study aimed to evaluate the effective photosynthetic quantum yield $\left(\Phi_{\text {PSII }}\right)$ and the Photochemical Reflectance Index (PRI) for assessment of photosynthetic performance of two Umbilicaria lichens during gradual desiccation of their thalli. U. cylindrica and $U$. decussata exhibited curvilinear relationship (S-shape curve) of decreasing $\Phi_{\mathrm{PSII}}$ values with decreasing water potential (WP) of thalli. During initial phase of desiccation (WP from 0 to $-10 \mathrm{MPa}$ ), no decrease of $\Phi_{\text {PSII }}$ was apparent, further desiccation (WP from -10 to $-20 \mathrm{MPa}$ ) led to fast $\Phi_{\mathrm{PSII}}$ decrease from 0.6 to 0.1 indicating strong inhibition of photosynthetic processes. Critical WP at which photosythetic processes are fully inhibited was found bellow $-25 \mathrm{MPa}$ in both lichen species. Photochemical Reflectance Index (PRI) exhibited curvilinear increase with thalli desiccation (decreasing WP). At full thallus hydration, the PRI reached the value of -0.18 in both species. Under strong dehydration (WP from -20 to -30 MPa), however, U. cylindrica showed somewhat lower value (-0.04) than U.decussata $(-0.02 \mathrm{MPa})$. PRI to WP relationship is discussed and compared to existing evidence from higher plants and poikilohydric organisms.
\end{abstract}

Key words: Quantum yield, water potential, chlorophyll fluorescence, Photochemical Reflectance Index, lichen, water stress

Abbreviations: $\mathrm{F}_{\mathrm{V}} / \mathrm{F}_{\mathrm{M}}$ - potential photosynthetic quantum yield of photosystem II, $\Phi_{\mathrm{PSII}}$ effective photosynthetic quantum yield of photosystem II, NDVI - normalized differentiate vegetation index, NPQ - non-photochemical quenching, PPFD photosynthetic photon flux density, PRI - Photochemical Reflectance Index, PS II photosystem II, WP - water potential

Received September 15, 2012, accepted October 15, 2012.

*Corresponding author: mbartak@sci.muni.cz

Acknowledgement: The work reported here was supported by the project No. LM20010009 (CzechPolar) provided by the Czech Ministry of Education, Youth and Sports. The authors are grateful for the possibility to use the infrastructure of the CzechPolar. The authors are grateful to Dr. M. Forbelská (Masaryk University, Brno) for the help she provided during mathematical data processing. 


\section{Introduction}

Lichens are poikilohydric symbiotic organisms exhibiting maximum photosynthetic rate at optimum hydration that is species-specific. If hydration of lichens decreases below such optimum due to progressive desiccation, photosynthetic processes are gradually inhibited. During desiccation of lichen thallus, several biochemical and biophysical mechanism are activated to minimize damages to photobionts (Kranner et al. 2008) and their photosynthetizing pigments (Zorn at al. 2001). Initial phase of desiccation is typical by partial water loss from a thallus but no reduction of photosynthetic rate is apparent. More pronounced water loss, however, leads to fast decrease of photosynthetic processes. At severe dehydration of thalli, full inhibition of photosynthesis occurs. Within last couple of years, the dependence of photosynthesis of numerous Arctic and Antarctic lichens on thallus dehydration expressed as water potential has been investigated in our laboratory (see e.g. Barták et al. 2005). Representatives of genus Umbilicaria typically show substantial photosynthesis even at strong dehydration, i.e. within water potential (WP) range from -15 to $-20 \mathrm{MPa}$. In this study, we investigated two lichens form Svalbard (Umbilicaria cylindrica and Umbilicaria decussata) during gradual desiccation using measurements of chlorophyll fluorescence, effective quantum yield of photosynthetic processes in photosystem II $\left(\Phi_{\mathrm{PSII}}\right)$ of symbiotic alga in particular. The other aim of this study was to evaluate critical water potential (WP) at which photosynthetic processes are fully inhibited and compare to existing data from other lichen species.

The Photochemical Reflectance Index (PRI) is based on a reflectance measure- ment developed by Gamon (1992). The PRI uses two wavelengths, $531 \mathrm{~nm}$ and $570 \mathrm{~nm}$, respectively.

$$
\mathrm{PRI}=(\mathrm{R} 531-\mathrm{R} 570) /(\mathrm{R} 531+\mathrm{R} 570)
$$

Reflectance at $531 \mathrm{~nm}$ is mostly affected by the changes in carotenoid pigments, especially xanthophyll-cycle pigments. Therefore, numeric value of the PRI is sensitive to zeaxanthin formation which is activated under high light conditions and water stress in photosynthetizing tissue. PRI is thus used as an effective indicator of photoinhibitory and water stress in higher plants (e.g. Liu et al. 2012). In most studies, PRI is well related to non-photochemical quenching of access light energy absorbed by photosynthetic pigments in chloroplasts. It is because of substantial involvement of light- or drought-induced zeaxanthin formation into protective mechanisms of non-photochemical nature activated during initial and the following phases of stress in plants. The PRI is generally used for the assessment of changes in carotenoid content (Sims et Gamon 2002), interconversion of xanthophyll-cycle pigments in particular. Some of recent studies, however, pointed out that PRI might be used also as an indicator of water stress in plants (Thenot et al. 2002). For lichens, no such study investigating PRI in relation to the hydration status of thallus has been performed since NDVI index is generally used much more frequently than PRI (Gloser et Gloser 2007). Moreover, the use of NDVI is recently devoted to large scale studies exploiting remote sensing approach with the main emphasis given to the identification of components of vegetation cover (e.g. Rees 2012). 
Recently, there is trend to use several biophysical methods to measure photosynthesis in plants in order to identify limiting factors of photosynthesis of particular species. Over last few decades, chlorophyll fluorescence technique has been used frequently in the assessment of the extent of stress in photosynthetic apparatus in plants. That was why we decided to measure water limitation of photosynthesis in desiccating lichens by chlorophyll fluorescence and ongoing changes in PRI indicating the extent of water stress. Recently, simultaneous measurements of $\mathrm{Chl}$ fluorescence data and PRI are used to evaluate the effect of leaf development stage (Rahimzadeh-Bajgiran et al. 2012), radiation and temperature variation during growing season (Weng et al. 2006), actual leaf temperature (Inamullah et Isoda 2005), and exposure to ozone (Meroni et al. 2008) on functioning of photosynthetic apparatus of higher plants. In poikilohydric plants and organisms, however, such approach is used only to a limited extent. In our study, we focused on simultaneous measurements of PRI and effective quantum yield of photosynthetic processes in photosystem II ( $\left.\Phi_{\text {PSII }}\right)$. Close correlation is found between PRI and $\Phi_{\mathrm{PSII}}$ (e.g. Gamon et al. 1997) in higher plants. However, in poikilohydric autotrophic organisms, lichens at different level of hydration in particular, the PRI to $\Phi_{\text {PSII }}$ relationship, has not yet beeen investigated. Only scarce data are available on PRI and potential yield of photochemical reactions in PS II $\left(\mathrm{F}_{\mathrm{V}} / \mathrm{F}_{\mathrm{M}}\right)$ in desiccating lichens. Yamano et al. (2006) found linear relationship between $\mathrm{PRI}$ and $\mathrm{F}_{\mathrm{V}} / \mathrm{F}_{\mathrm{M}}$ in lichens forming desert soil crust. We therefore hypothesized, that reasonable correlation should be found between $\Phi_{\mathrm{PSII}}$ and PRI when measured on gradually desiccating lichen thalli. Combination of the two biophysical methods is beneficial because it brings a deeper insight into functioning of chloroplastic photosynthetic apparatus under stress.

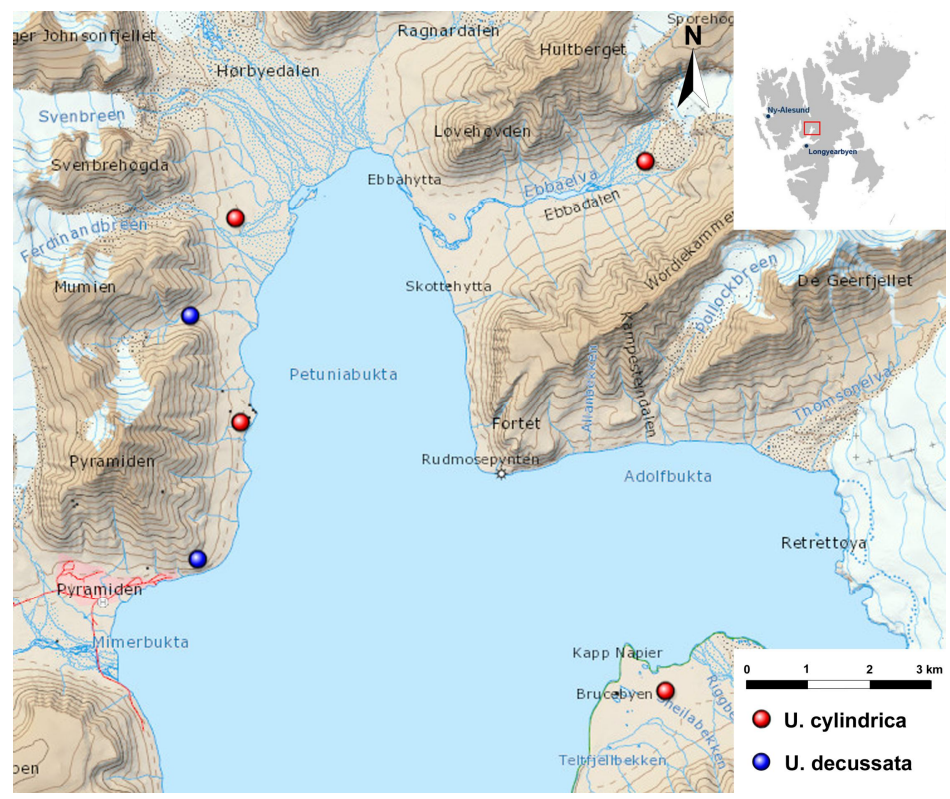

Fig. 1. Map of Central Svalbard with the indication of the plots at which thalli of $U$. cylindrica and $U$. decussata were collected during field campaign in Arctic summer 2012. Modified map extract (source: NPI: http://toposvalbard.npolar.no/). 


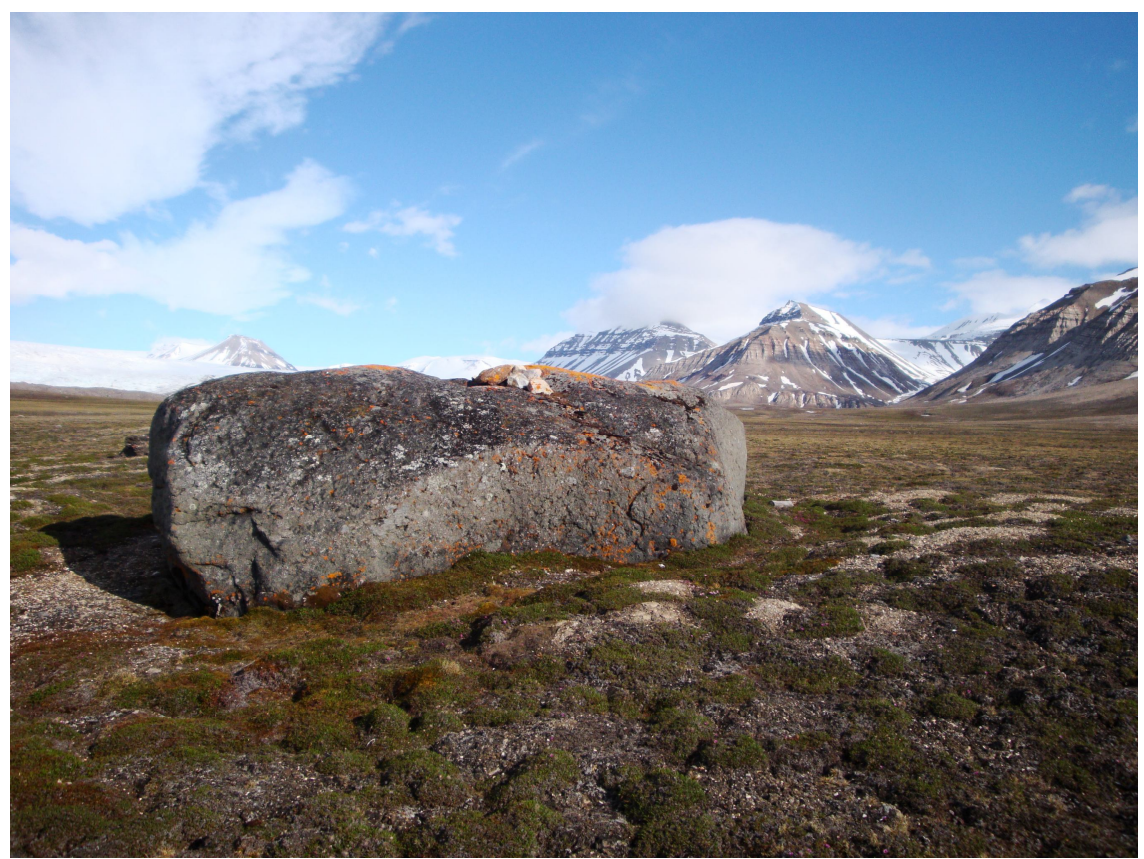

Fig. 2. One of collection plots with high occurence of $U$. cylindrica and U. decussata. The thalli of both species were abundant mainly on rock surfaces, several centimeters above ground level where the upper margin of snow cover occurs.

\section{Material and Methods}

Samples of lichen Umbilicaria cylindrica were collected in the first half of July 2012 on several field locations of central part of Spitsbergen Island $\left(16^{\circ} \mathrm{E}\right.$, $78^{\circ} \mathrm{N}$; Svalbard), in the vicinity of Petuniabukta (see Fig. 1). All samples grew on stones and rocks near the coast in the elevation to $100 \mathrm{~m}$ above sea level. Typical thalli of Umbilicaria cylindrica are round-shaped. It is grey or brownishgrey and often divided into multiple lobes. For the experiment, we selected thalli sized at least $3 \mathrm{~cm}$ in diameter (see Fig. 3). Umbilicaria decussata has more or less round-shaped thallus, typically 1 to $5 \mathrm{~cm}$ in diameter. Thallus upper surface is light gray to dark gray or brownish gray, with sharp ridges radiating from the central point. Lower surface of thallus is white (see Fig. 3). Thalli, typically attached at central point (umbilicus), were cut of by sharp blade from surface of stones (Fig. 2) and hydrated for 24 hours. Fully hydrated thalli were placed in plastic dishes and subjected to slow desiccation at room temperature $\left(25^{\circ} \mathrm{C}, 40 \% \mathrm{RH}\right)$. Dependence of quantum yield of photochemical reactions in photosystem II $\left(\Phi_{\mathrm{PSII}}\right)$ on water potential (WP) of thalli was determined using PAM-2000 modulated fluorometer (Walz, Germany) connected to a portable computer and a dew point water potential meter WP4T (Decagon Devices, USA) with programmed temperature control. Determination of WP by the device was based on chilled-mirror dewpoint technique. The instrument enables the measurement of samples up to $40 \mathrm{~mm}$ in diameter and $10 \mathrm{~mm}$ in height with an accuracy of $0.1 \mathrm{MPa}$. 

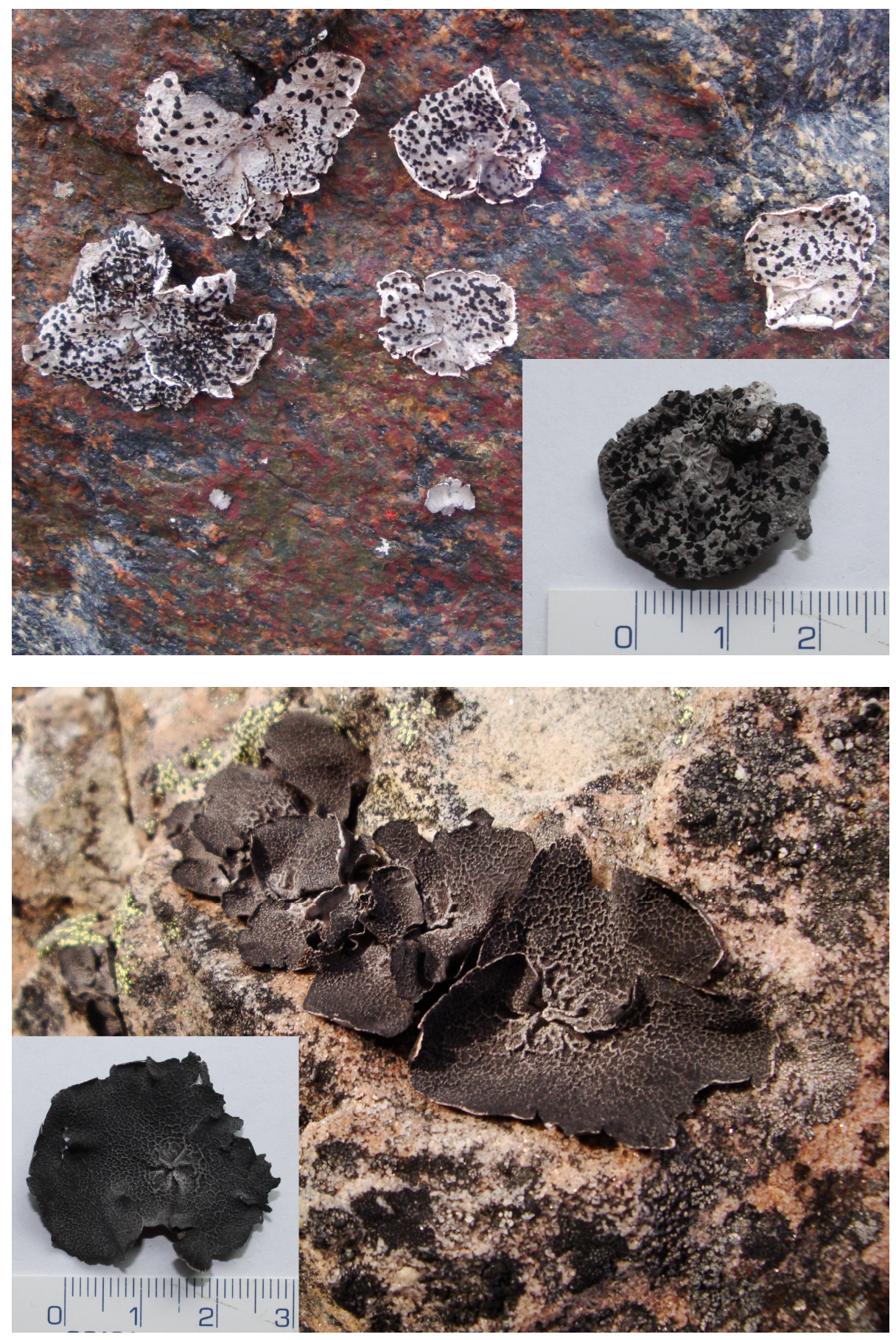

Fig. 3. Typical thallus of $U$. cylindrica (upper) and $U$. decussata (lower). The photographs were taken with dry thalli. 
For WP determination, samples were placed into a measuring chamber of the device and equilibrated to constant relative humidity. After measuring of WP, the same sample was exposed for $5 \mathrm{~min}$ to constant artificial irradiance of $40 \mu \mathrm{mol}$ $\mathrm{m}^{-2} \mathrm{~s}^{-1}$ photosynthetic photon fluence density (PPFD) and then the $\Phi_{\text {PSII }}$ was immediately measured. LED was used as the source of PPFD and the value of PPFD was determined using radiometer EMS-12 (Photon System Instruments, Czech Republic). After $\Phi_{\text {PSII }}$ measurement, Photochemical Reflectance Index (PRI) was determined. For PRI measurements, a PlantPen PRI 200 (Photon System Instruments, Czech Republic) was used. The whole cycle of measurements was repeated during the desiccation period until $\Phi_{\text {PSII }}$ reached zero.

\section{Results}

At full thallus hydration, suprasaturation effect on photosynthesis was observed in $U$. cylindrica but not in $U$. decussata (see Fig. 4, the $\Phi_{\mathrm{PSII}}$ values at $\mathrm{WP}=0$ ). Either no or mild decrease of $\Phi_{\mathrm{PSII}}$ was observed in both species within the WP range of 0 to $-10 \mathrm{MPa}$ which reflects initial phase of thallus dehydration. Further decrease of water potential (below $-10 \mathrm{MPa}$ ) led to substantial and rapid decrease of $\Phi_{\text {PSII }}$ in both experimental lichen species. Significant limitation of photochemical processes in PS II appeared at WP below -20 MPa. Critical WP at which $\Phi_{\text {PSII }}$ was close to zero differed between species. Full inhibition of photosynthetic processes was reached at about $-25 \mathrm{MPa}$ in $U$. decussata while the same was apparent at lower values of about -30 $\mathrm{MPa}$ in U. cylindrica.

Relation between PRI and WP was curvilinear and exhibited PRI increase with WP decrease (Fig. 5). The relationship was similar in both investigated species. At full thallus hydration, PRI values reached the values between -0.19 and -0.17 . When very limited loss of water from lichen thallus occured (WP decrease from 0 to $-2 \mathrm{MPa}$ ), PRI increased up to the values about -0.07 ( $U$. cylindrica) and -0.05 ( $U$. decussata). There were also some minor interspecific differences found in bending of the PRI to WP relationship as well as the maximum PRI values found at heavily desiccated thalli (see data points in Fig. 4). While in U. cylindrica the PRI maximum was about -0.04 , it reached slightly higher values in $U$. decussata $(-0.03$ to -0.02$)$. Slight differences, however, were found in the PRI to $\Phi_{\text {PSII }}$ relation (Fig. 6). The relation was of curvilinear shape. Under full hydration and initial phases of water loss, i.e. at $\Phi_{\mathrm{PSII}}$ ranging from 0.7 to 0.6 , PRI values increased rapidly, typically from -0.18 to -0.06 . This was found in $U$. cylindrica while the increase was much less pronounced in $U$. decussata (from -0.10 to -0.06). Further decrease in the intrathalline water content led to the decrease in $\Phi_{\mathrm{PSII}}$ (from 0.4 to 0.1 ), however, PRI values showed only minor increase from -0.06 to -0.04 in $U$. cylindrica and -0.06 to -0.02 in U. decussata. 

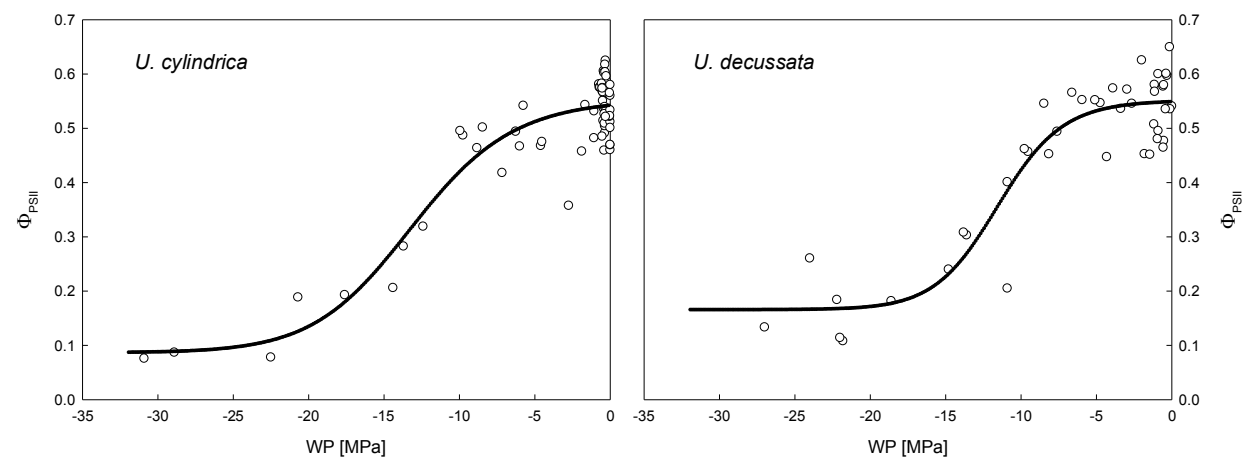

Fig. 4. Relation between the effective quantum yield of photosystem II ( $\left.\Phi_{\mathrm{PSII}}\right)$ and water potential (WP) recorded during desiccation of lichen thalli from wet (WP $=0 \mathrm{MPa}$ ) to dry (WP below -25 $\mathrm{MPa}$ ) state. The curve is the best fit of log-logistic S-curve.
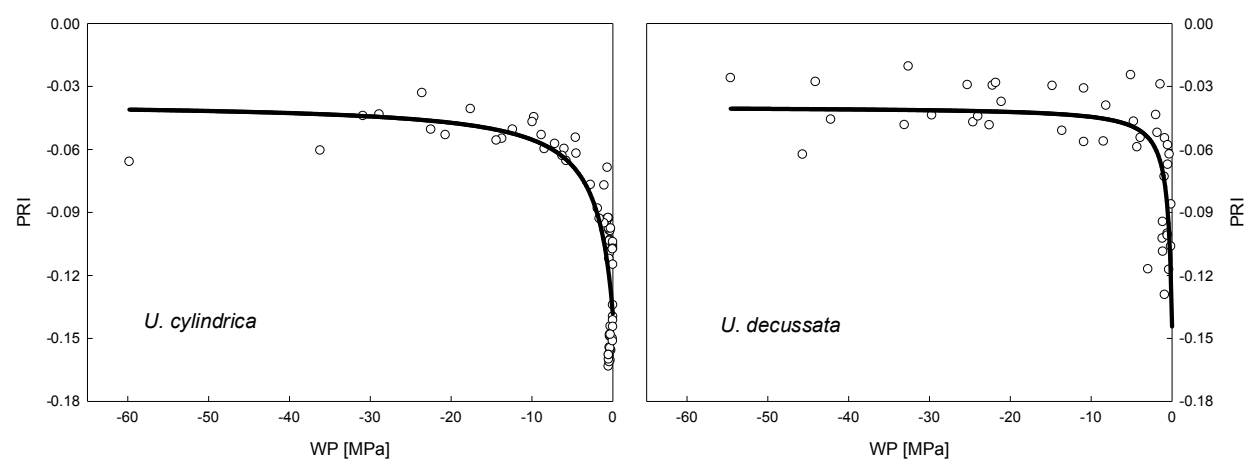

Fig. 5. Relation of Photochemical Reflectance Index (PRI). to water potential (WP) recorded in $U$. cylindrica and $U$. decussata during gradual desiccation form full thalli hydration ( $\mathrm{WP}=0 \mathrm{MPa}$ ) to fully dehydrated thalli.
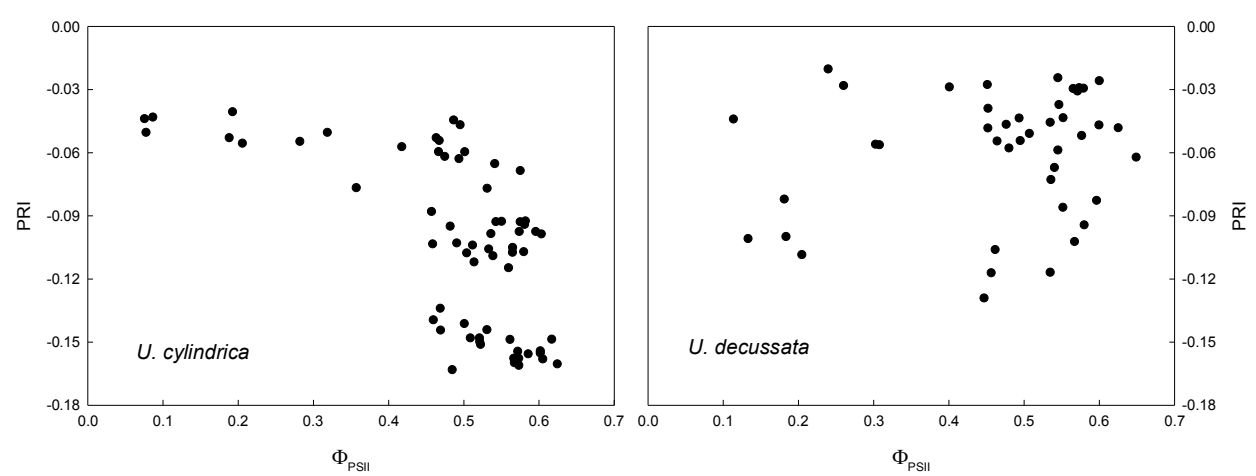

Fig. 6. Relation of effective quantum yield of photosynthetic processes $\left(\Phi_{\mathrm{PSII}}\right)$ to Photochemical Reflectance Index (PRI). Data points were recorded during gradual desiccation of $U$. cylindrica and $U$. decussata thalli. 


\section{Discussion}

Critical WP ranged between -25 and -30 MPa for both investigated Umbilicaria species. This was well comparable to the WP values found in the earlier studies done on Antarctic species. Critical WP was found -25 MPa in Xanthoria elegans (Barták et al. 2005) and -30 MPa for lichenized Nostoc (Moudrá et Barták, 2009). There are, however, indications that interspecific differences exist in critical WP of lichen species growing in polar regions. Results obtained for lichen species collected at Galindez Island (Antarctica) and measured by the same method showed that Umbilicaria antarctica had critical WP of about $-40 \mathrm{MPa}$, while much higher values were found for Stereocaulon (-30 $\mathrm{MPa})$ - Barták et Gloser (2004).

Our data supports the evidence from literature, that gradual loss of water from lichen thalli leads to decrease in rate of photochemical processes of photosynthesis, $\Phi_{\text {PSII }}$ in particular. Dehydrationdependent decrease in photochemistry leads to the decline biochemical part of photosynthesis as proven by numerous gas exchange studies in desiccating lichens in a laboratory (e.g. Lange et al. 2001) or in the field (Reiter et al. 2008). Such dehydration-dependent decrease in photosynthesis is accompanied by the activation of protective mechanisms that protect components of photosystem II from damages. These mechanisms are similar to those activated in lichens during photoinhibition and include interconversion of xantophyll cycle pigments (Calatayud et al. 1997, Vráblíková et al. 2005). They comprise several pathways of thermal energy dissipation (Heber et al. 2007, 2010) that act in reaction centers of PS II during lichen dehydration. To protect themselves from overenergization, reaction centers of PS II are converted from energy absorbing centers to energy dissipating centers at certain level of dehydration (Heber et al. 2011). Presence of strong quencher in core of PS II and/or PS II antennae is reported from lichens desiccating on light (Veerman et al. 2007), however its chemical structure is not known. Recent studies showed, that the association of fungal and algal partners plays also important role since the lichen association showed higher resistance to dehydration stress than isolatated photobionts (Kosugi et al. 2006).

In higher plants, positive relation between PRI and $\Phi_{\mathrm{PSII}}$ has been reported for a variety of species and experimental treatments. The relation, however, differs from what we found in U. cylindrica and $U$. decussata. Inamullah et Isoda (2005) showed that different irrigation regimen of Gossypium hirsutum and Glycine max resulted in a decrease of $\Phi_{\text {II }}$ with water limitation. In these plants, PRI was possitively correlated with $\Phi_{\mathrm{PSII}}$, i.e. PRI declined with pronounced water limitation. Similar response was found by Stylinski et al. (2000) who reported that an increase in photosynthetic electron rate brought an increase in PRI in Quercus pubescenc leaves exposed to natural and elevated $\mathrm{CO}_{2}$ concentrations. Positive relation between $\Phi_{\text {PSII }}$ and PRI was also found in grasses (Weng et al. 2012) as well as two srubs Baccharis halimifolia and Myrica cerifera exposed to salt stress (Zinnert et al. 2012).

For poikilohydric autotrophic organisms, relation between PRI and $\Phi_{\text {PSII }}$ has been investigated only exceptionally. In mosses, Van Gaalen et al. (2007) showed decreasing values of nonphotochemical quenching (NPQ) with increasing PRI in desiccating Sphagnum sp. The same authors reported linear increase of PRI with Sphagnum dehydration expressed as relative water content. We may, therefore, conclude that reasonable agreement exists between our findings of PRI to WP relationship and available data from poikilohydric moss, because both 
they show the PRI increase with water loss from thalli. The PRI to WP relationship found in this study showed, however, curvilinear shape. This might be explained either by optical properties of desiccating Umbilicaria sp. thalli that differ from those of Spagnum ones. The other explanation is that relation of WP to relative water content is curvilinear in U. cylindrica (our data, not shown). General conclusion from our data is that PRI increases with decreasing WP in both Umbilicaria species investigated in this study. This conclusion can be supported also by the data presented by Gauslaa (1984). In his paper, spectral reflectance curves are given for several species of Umbilicaria genus. We used the data derived from the curves that he recorded for wet and dry thalli. We calculated PRI values (not shown here) for several Umbilicaria species. In U. rigida, U. spodochlora and $U$. vellea, we found an increase of PRI values in dry thalli which support the general trend found for $U$. cylindrica and U. decussata in Fig. 5.

\section{Conclusion}

The results indicated high degree of tolerance of genus Umbilicaria species to water stress and their ability to photosynthesize even under substantial water loss from their thalli. Moreover, critical water potential values were below -25 $\mathrm{MPa}$ which indicates the ability of the two lichen species to perform photochemical processes of photosynthesis at strongly desiccated state of a thallus as well (Jupa et Barták 2012). We may, therefore, conclude that $U$. cylindrica and $U$. decussata may thrive well in polar ecosystems with limited water availability and short period of thallus hydration.

\section{References}

BARTÁk, M., Gloser, J. (2004): Activity of primary photosynthetic processes in some Antarctic lichens and mosses at decreasing water potential of their thalli. Terra Nostra, 4: 106-107.

BARTÁK, M., Gloser, J. and HÁJEK, J. (2005): Visualized photosynthetic characteristics of the lichen Xanthoria elegans related to daily courses of light, temperature and hydration: a field study from Galindez Island, maritime Antarctica. The Lichenologist, 37: 433-443.

Calatayud, A., Deltoro, V.I., Barreno, E. and Valle-Tascon, S. (1997): Changes in vivo chlorophyll fluorescence quenching in lichen thalli as a function of water content and suggestion of zeaxanthin-associated photoprotection. Physiologia Plantarum, 101: 93-102.

Gamon, J.A., Penuelas J. and Field C.B. (1992): A Narrow-Waveband Spectral Index That Tracks Diurnal Changes in Photosynthetic Efficiency. Remote Sensing of Environment, 41: 3544.

Gamon, J.A., Serrano L. and Surfus J.S. (1997): The Photochemical Reflectance Index: An Optical Indicator of Photosynthetic Radiation Use Efficiency Across Species, Functional Types and Nutrient Levels. Oecologia, 112: 492-501.

GauslaA, Y. (1984): Heat resistance and energy budget in different Scandinavian plants. Holarctic Ecology, 7: 1-78.

Gloser, J., Gloser, V. (2007): Changes in spectral reflectance of a foliar lichen Umbilicaria hirsuta during desiccation. Biologia Plantarum, 51:395-398.

Heber, U., Azarkovich, M. and Shuvalov, V. (2007): Activation of mechanisms of photoprotection by desiccation and by light: poikilohydric photoautotrophs. Journal of Experimental Botany, 58: 2745-2759. 
Heber, U., Bilger, W., TÜrk, R. and Lange, O.L. (2010): Photoprotection of reaction centres in photosynthetic organisms: mechanisms of thermal energy dissipation in desiccated thalli of the lichen Lobaria pulmonaria. New Phytologist, 185: 459-470.

Heber, U., Soni, V. and Strasser R. J. (2011): Photoprotection of reaction centers: thermal dissipation of absorbed light energy vs charge separation in lichens. Physiologia Plantarum, 142: $65-78$.

InAmullah, IsOdA, A. (2005): Adaptive responses of soybean and cotton to water stress. II. Changes in $\mathrm{CO}_{2}$ assimilation rates, chlorophyll fluorescence and photochemuical reflectance index in relation to leaf temperature. Plant Production Science, 8: 131-138.

JuPA, R., BARTÁK, M. (2012): Dehydration-dependent inhibition of photosynthetic processes in two lichen species from Svalbard: a fluorometric study. In: A. Bernardová, J. Kavan, O. Strunecký (eds.): Polar Ecology Conference 2012, 30 ${ }^{\text {th }}$ September- $4^{\text {th }}$ October 2012, České Budějovice, Czech Republic. Abstracts\&Contact List. pp. 45-46, ISBN 978-80-7394-375-2.

KranNER, I., BeCKETT, R. and Hochman, A. (2008): Desiccation-tolerance in lichens: a review. Bryologist, 111: 576-593.

Kosugi, M., Arita, M., Shizuma, R., Moriyama, Y., Kashino, Y., Koike, H. and Satoh, K. (2006): Responses to Desiccation Stress in Lichens are Different from Those in Their Photobionts. Plant and Cell Physiology, 50: 879-888.

Lange, O.L., Green, T.G.A. and Heber, U. (2001): Hydration-dependent photosynthetic production of lichens: what do laboratory studies tell us about field performance? Journal of Experimental Botany, 52: 2033-2042.

Liu, B., Tong, Q.X., Zhang, L.F., Zhang, X., Yue, Y.M. and Zhang, B. (2012): Monitoring spatio-temporal spectral characteristics of leaves of karst plant during dehydration using a field imaging spectrometer system. Spectroscopy and Spectral Analysis, 32: 1460-1465.

Meroni, M., Rossini, M., Picchi, V., Panigada, C., Cogliati, S., Nali, C. and Colombo, R. (2008): Assessing steady-state fluorescence and PRI from hyperspectral proximal sensing as early indicators of plant stress: The case of ozone exposure. Sensors, 8: 1740-1754.

MOUDRÁ, A., BARTÁK, M. (2009): Comparative study of dehydration-response curves of photosynthesis in Antarctic lichen and Nostoc commune. In: M. Barták, J. Hájek, P.Váczi (eds.): Structure and Function of Antarctic Terrestrial Ecosystems. Book of Abstracts and Contributed Papers. Conference, Brno, October 22-23, 2009. Masaryk University, Brno, Czech Republic, pp. 59-61.

Rahimzadeh-Bajgiran, P., Munehiro, M. and Omasa K. (2012): Relationships between the photochemical reflectance index (PRI) and chlorophyll fluorescence parameters and plant pigment indices at different leaf growth stages. Photosynthesis Research, 113: 261-271.

REES, W.G. (2012): Automated spaceborne detection of degraded vegetation around Monchegorsk, Kola Peninsula, Russia. Polar Record, 48: 107-112.

Reiter, R., Höftberger, M., Green, T.G.A. and TÜRK, R. (2008): Photosynthesis of lichens from lichen-dominated communities in the alpine/nival belt of the Alps - II: Laboratory and field measurements of $\mathrm{CO}_{2}$ exchange and water relations. Flora - Morphology, Distribution, Functional Ecology of Plants, 203: 34-46.

Sims, D.A., Gamon, J.A. (2002): relationship between leaf pigment content and spectral reflectance across a wide range of species, leaf structures and developmental stages. Remote Sensing of Environment, 81: 337-354.

Stylinski, C.D., Oechel, W.C., Gamon, J.A., Tissue, D.T., Miglietta, F. and Raschi, A. (2000): Effects of lifelong $\left[\mathrm{CO}_{2}\right]$ enrichment on carboxylation and light utilization of Quercus pubescens Willd. examined with gas exchange, biochemistry and optical techniques. Plant, Cell and Environment, 23: 1353-1362.

Thenot, F., Méthy, M. and Winkel, T. (2002): The Photochemical Reflectance Index (PRI) as a water-stress index. International Journal of Remote Sensing, 23: 5135-5139.

Veerman, J., Vasil'ev, S., Paton, G.D., Ramanauskas, J. and Bruce, D. (2007): Photoprotection in the lichen Parmelia sulcata: The origins of desiccation-induced fluorescence quenching. Plant Physiology, 145: 997-1005. 
Van Gaalen, K.E., Flanagan, L.B. and Peddle, D.R. (2007): Photosynthesis, chlorophyll fluorescence and spectral reflectance in Sphagnum moss at varying water contents. Oecologia, 153:19-28.

VRÁBLÍKOVÁ, H., BARTÁK, M. and WÖNISCH A. (2005): Changes in glutathione and xanthophyll cycle pigments in the high light-stressed lichens Umbilicaria antarctica and Lasallia pustulata. Journal of Photochemistry and Photobiology B-Biology, 79: 35-41.

Weng, J.H., LiaO, T.S., Hwang, M.Y., Chung, C.C., Lin, C.P. and Chu, C.H. (2006): Seasonal variation in photosystem II efficiency and photochemical reflectance index of evergreen trees and perennial grasses growing at low and high elevations in subtropical Taiwan. Tree Physiology, 26: 1097-1104.

WENG, J.-H., WONG, S.-L., LAI, K.-M. and Lin, R.-J. (2012): Relationships between photosystem II efficiency and photochemical reflectance index under different levels of illumination: comparison among species grown at high and low elevations through different seasons. TreesStructure and Function, 26: 343-351.

Yamano, H., Chen, J., Zhang, Y. and TAmuRA, M. (2006): Relating photosynthesis of biological soil crusts with reflectance: preliminary assessment based on a hydration experiment. International Journal of Remote Sensing, 27: 5393-5399.

Zinnert, J.C., Nelson, J.D. and Hoffman, A.M. (2012): Effects of salinity on physiological responses and the photochemical reflectance index in two co-occurring coastal shrubs. Plant and Soil, 354: 45-55.

Zorn, M., Pfeifhofer, H.W., GriLl, D. and Kranner, I. (2001): Responses of plastid pigments to desiccation and rehydration in the desert lichen Ramalina maciformis. Symbiosis, 31: 201-211. 